\title{
DO DIÁLOGO TRANSCONSTITUCIONAL ENTRE A CULTURA INDÍGENA E A ORDEM CONSTITUCIONAL BRASILEIRA
}

\section{TRANSCONSTITUTIONAL TALK BETWEEN THE INDIGENOUS CULTURE AND THE BRAZILIAN CONSTITUTIONAL ORDER}

\author{
${ }^{1}$ Bruna Escobar Teixeira \\ ${ }^{2}$ Péricles Stehmann Nunes
}

\section{RESUMO}

A pesquisa busca compreender os conflitos culturais existentes no território brasileiro entre a cultura de certos povos indígenas que se assimilam a uma ordem normativa própria e a ordem constitucional brasileira, abordando, para isso, o Projeto de Lei n. 1057/2007, que trata sobre o caso de infanticídio em algumas tradições indígena. Tem por objetivo analisar o tema sob o enfoque da teoria do transconstitucionalismo, como forma de construir uma racionalidade transversal que propõe o diálogo proveitoso entre as ordens jurídicas. $\mathrm{O}$ resultado do artigo aponta especificamente, a mediação que busca a resolução dos litígios, possibilitando uma visão de alteridade.

Palavras-Chave: Cultura indígena; Mediação; Transconstitucionalismo.

\begin{abstract}
The research seeks to comprehend the existing cultural conflicts in Brazilian Territory between the culture of certain indigenous cultures, which are similar to their own normative order and the Brazilian Constitutional Order, approaching for that the Law Project no. 1057/2007, which is about the infanticide in some indigenous traditions. It aims to analyse the matter under the Transconstitutional Theory as a means of building a transversal rationality that proposes a profitable dialog amongst the juridical orders. The result of the article points specifically to the mediation that seeks the litigation settlement, making possible a vision of otherness.
\end{abstract}

Keywords: Indigenous Culture; Transconstitutional; Mediation.

\footnotetext{
${ }^{1}$ Mestre com Área de Concentração em Direitos Especiais, pela Universidade Regional Integrada do Alto Uruguai e das Missões - URI, Rio Grande do Sul. E-mail: bruna-escobar@ hotmail.com

${ }^{2}$ Mestre com Área de Concentração em Direitos Especiais, pela Universidade Regional Integrada do Alto Uruguai e das Missões - URI, Rio Grande do Sul. E-mail: periclessn@gmail.com
} 


\section{INTRODUÇÃO}

Com a globalização, configurou-se a ideia de que o mundo passa a ser entrelaçado entre todos os seus habitantes. Em razão disso, as resoluções dos conflitos humanos extrapolam os limites constitucionais inserindo-se a uma rede transconstitucional de conversações entre ordens jurídicas estatais e as ordens extraestatais de coletividades nativas, ou seja, de povos originários.

Os povos nativos possuem costumes que se assimilam a uma ordem normativa própria. A partir dessa prerrogativa, surgem questões antropológico-culturais que são muitos fortes e muitas vezes entram em conflito com o ordenamento jurídico atual. Diante disso, o trabalho pretende estudar até que ponto é possível estabelecer um diálogo transconstitucional entre as comunidades indígenas e ordem constitucional brasileira.

Assim, para alcançar o objetivo central acima exposto, essa pesquisa se propõe a analisar os problemas do diálogo entre ordens jurídicas que visam soluções de problemas tipicamente constitucionais. Em vista disso, o presente artigo aborda sobre o Projeto de Lei n. 1057/2007, que trata sobre o caso de infanticídio em algumas tradições indígenas, analisado este tema por meio de premissas do transconstitucionalismo, como forma de construir uma racionalidade transversal que propõe o diálogo proveitoso entre a ordem jurídica nacional e as culturas desses povos, especificamente a mediação que busca a resolução dos litígios.

\section{O CONFLITO ENTRE A ORDEM NORMATIVA DE COMUNIDADES INDÍGENAS E A ORDEM CONSTITUCIONAL BRASILEIRA}

Entende-se a situação conflituosa existente nas práticas presentes em diversos grupos sociais. Um dos casos que explica a colisão entre a cultura indígena e a ordem constitucional vem a ser sobre os índios Suruahá, que originou o Projeto de Lei n. 1057/2007, conhecido como "Lei Muwaji", em homenagem a uma mãe da tribo que se rebelou contra a tradição de sua comunidade e salvou a vida da filha que seria morta por ter nascido deficiente. O projeto que ainda tramita no Congresso Nacional dispõe sobre o combate a práticas tradicionais nocivas e à proteção dos direitos fundamentais de crianças indígenas, bem como pertencentes a outras sociedades ditas não tradicionais.

O Projeto de Lei proposto pelo Deputado Federal Henrique Afonso, representante do Estado do Acre, possui como princípio basilar o respeito aos direitos humanos fundamentais estabelecidos na Constituição Federal e internacionalmente reconhecidos. O Projeto considera 
nociva qualquer prática que atente contra a vida e a integridade física-psíquica, como se pode observar no artigo $2^{\circ}$ do Projeto de Lei.

A justificativa baseia-se em instrumentos jurídicos que acentuam os direitos das mulheres e crianças perante costumes nativos. Assim, visa cumprir dispositivos como o Decreto 99.710 de 1990, que promulga a Convenção sobre os Direitos das Crianças que reconhece o direito à vida como inerente a toda criança. Também visa executar recomendação da Assembleia Geral das Nações Unidas, como estabelecido na Resolução A/RES/56/128 de 2002, a qual combate as práticas tradicionais nocivas. Igualmente, cumpre a Resolução A/S-27/19, também da Assembleia Geral da ONU, que coloca em prioridade os interesses das crianças.

Destaca-se a proteção da Constituição Federal de 1988, em seu artigo 227, que garante o direito à vida e à saúde a todas as crianças, bem como, essa proteção é garantida pelo artigo $7^{\circ}$ do Estatuto da Criança e do Adolescente. Ressalta-se, ainda, o Código Civil, em seu artigo $1^{\circ}$, no qual determina que toda pessoa é capaz de direitos e deveres na ordem civil e, em seu artigo $2^{\circ}$, que o começo da personalidade civil se dá com o nascimento com vida. Os Instrumentos normativos mencionados estão indicados como justificativa no Projeto de Lei.

Do mesmo modo, outra justificativa do Projeto de Lei 1057/07 cita que é importante destacar que a cultura é dinâmica e não imutável. A cultura não é o bem
maior a ser tutelado, mas sim o ser humano, no intento de lhe propiciar o bem-estar e
minimizar seu sofrimento. Os direitos humanos perdem, completamente, o seu sentido
de existir, se o ser humano for retirado do centro do discurso e da práxis. Portanto, a
tolerância (no sentido de aceitação, reconhecimento da legitimidade) em relação à
diversidade cultural deve ser norteada pelo respeito aos direitos humanos (2007, p.
03).

O mencionado Projeto foi apresentado em 11 de maio de 2007, aprovado pela Comissão de Direitos Humanos e Minorias pelo parecer da Relatora Janete Rocha Pietá em 01 de junho de 2011, aprovado pela Comissão de Constituição e Justiça e de Cidadania em 02 de julho de 2013. A redação final do Projeto, assinado pelo relator Deputado Marcos Rogério, foi aprovada em 26 de agosto de 2015. Por fim, a mesa diretora da Câmara dos Deputados remeteu a matéria ao Senado Federal por meio do Ofício n. 510/15/PS-GSE em 02 de setembro de 2015.

Conforme o doutrinador Marcelo Neves, os elaboradores e defensores "partiram primariamente da absolutização do direito fundamental individual à vida, nos termos da moral cristã ocidental. Secundariamente, também contribuiu para a proposição do Projeto o direito fundamental da mãe à maternidade" (2014, p. 203). 
Entretanto, para os contrários ao Projeto, essa simples criminalização pode ser um "verdadeiro genocídio cultural, a destruição da própria comunidade, destruindo suas crenças mais profundas" (NEVES, 2014, p. 203).

Ademais, há quem defenda que a proposta é inconstitucional, pois nega a identidade cultural aos povos indígenas, conforme artigo $215, \S 1^{\circ}$ da Constituição Federal:

Art. 215. O Estado garantirá a todos o pleno exercício dos direitos culturais e acesso às fontes da cultura nacional, e apoiará e incentivará a valorização e a difusão das manifestações culturais.

$\S 1^{\circ} \mathrm{O}$ Estado protegerá as manifestações das culturas populares, indígenas e afrobrasileiras, e das de outros grupos participantes do processo civilizatório nacional.

Segundo os costumes do povo Suruahá, habitantes do Munícipio de Tapauá, localizado no Estado do Amazonas, é obrigatório deixar morrer os recém-nascidos quando nascem com alguma deficiência física ou de saúde geral. (NEVES, 2014, p. 202).

A proposta sugerida pela Deputada Janete Rocha Pietá refuta o discurso de criminalização aproximando-se a ideia pela "valorização do protagonismo dos próprios índios, respeitando o pluralismo histórico, e confere atenção aos direitos individuais, que defendemos como essenciais a um tratamento constitucionalmente adequado da questão" (RODRIGUES, 2013, p. 496). Para a Deputada, são pertinentes políticas públicas conscientizadoras:

[...] são necessárias, sim, iniciativas de caráter conscientizador. Garantir o direito à vida das crianças, mulheres e famílias indígenas deve ser conseqüência da criação e implantação de políticas públicas. Paralelamente à valorização do direito à vida, tais iniciativas devem privilegiar o protagonismo da mulher indígena. Ademais, serão um princípio balizador fundamental os conceitos preconizados no art. 231 da Constituição Federal, que determina a proteção e respeito aos bens materiais e culturais dos indígenas (BRASIL, 2011).

[...] entendemos que devem ser criados um Conselho Nacional Indígena e um Conselho Tutelar Indígena. Tais órgãos teriam as atribuições de tratar, respectivamente, da discussão de questões culturais próprias dos grupos indígenas, elaborando campanhas de conscientização destinadas a promover mudanças entre esses grupos, e a promoção de medidas voltadas para o bem-estar das crianças e adolescentes indígenas. Nesse sentido, estaremos encaminhando a indicação de criação desses órgãos através dos mecanismos adequados. (BRASIL, 2011).

É possível, ainda, abordar o universalismo que consiste em corrente a qual "existem princípios morais universais, aplicáveis indistintamente a todas as sociedades, independentemente de suas peculiaridades culturais" (RODRIGUES, 2013, p. 497). Para a pesquisadora Maíra de Paula Barreto, “existem valores que são universais a todas as culturas, e estes valores fundamentam o princípio da universalidade dos direitos da personalidade" (2006, p. 10). Continua, ainda, Rodrigues afirmando que a "universalidade dos direitos 
previstos nos instrumentos internacionais não comportaria, por conseguinte, abertura interpretativa às especificidades locais" (2013, p. 498).

De outro extremo, analisando o relativismo cultural, Marianna Assunção Figueiredo Holanda (2008, p. 10) explica que os problemas dos Direitos Humanos universais é em relação "a sua interpretação exclusiva por parte de legisladores que compreende estes direitos como do indivíduo, com base em uma igualdade que não permite discriminar por 'raça, cor, gênero’ e, portanto, suprime a possibilidade de diferenças.

Essa situação causou polêmicas, pois de acordo com Neves, "se trata de um conflito praticamente insolúvel entre direito de autonomia cultural e direito à vida” (2014, p. 202). A questão também pode ser apresentada como um "conflito entre direito de autonomia cultural e direito das mulheres" (NEVES, 2014, p. 202).

De acordo com Guilherme Scotti Rodrigues, “o paradigma político e jurídico no tratamento das questões indígenas era o da integração ou aculturação" (2013, p. 491). Com a Constituição de 1988, as manifestações culturais passaram a ser consideradas um "direito das populações indígenas e de toda a sociedade brasileira, não uma situação transitória, vestígio do passado a exigir superação pela modernização, mas uma garantia do multiculturalismo e um elemento central para a autocompreensão ética nacional” (RODRIGUES, 2013, p. 491-492).

Ainda, segundo Rodrigues, a Constituição possui um compromisso com a garantia dos Direitos Humanos, "positivados como direitos fundamentais, impõe, todavia, um desafio: a interpretação de seus princípios universalistas em face de práticas tradicionais que possam implicar sua violação" (2013, p. 492).

Diante as discussões de convicções referente ao conflito entre normatividades culturais, há um caráter emancipatório dos princípios políticos e jurídicos na contemporaneidade. De início, conforme Rodrigues, “esses princípios cristalizaram-se, com tal força, que foram capazes de promover a dissolução das bases imóveis e absolutizadas da sociedade" (2013, p. 492). Assim, perante uma complexidade progressiva, nossos costumes e tradições passaram a solicitar uma análise referente a ética reflexiva.

De tal modo, essa fenda constitucional pluralista propicia, ao mesmo tempo, a vinculação aos direitos fundamentais e a reflexividade ética dos contornos de vidas culturais. Se, por um lado, encontram-se certas limitações nos direitos fundamentais referentes as "práticas tradicionais, por outro, operam simultaneamente como condição de possibilidade para a existência e a preservação das formas de vida tradicionais, em um mundo globalizante que tende a nivelar e assimilar alteridades" (RODRIGUES, 2013, p. 492-493). 
Para buscar dialogar adentro do conflito, a antropóloga Rita Laura Segato apresentou sua análise empírica sobre os Suruahá, na qual constatou que ocorreram mais mortes por suicídio que por infanticídio. Essa condição "aponta uma compreensão da vida bem distinta da concepção cristã ocidental. Entre essa comunidade indígena, a vida só tem sentido se não for marcada por excessivo sofrimento para o indivíduo e a comunidade, se for uma vida tranquila e amena" (SEGATO, 2011, p. 364).

Ademais, outro ponto de vista a ser observado é em relação à pratica Yanomami, "na qual a mulher tem direito absoluto sobre a vida dos seus recém-nascidos. O parto ocorre em ambiente natural, fora do contexto da vida social, deixando a opção à mãe" (NEVES, 2014, p. 204). O povo indígena possui uma visão peculiar sobre o contexto da vida social:

\footnotetext{
si no toca al bebé ni lo levanta en sus brazos, dejándolo en la tierra donde cayó, significa que éste no ha sido acogido en el mundo de la cultura y las relaciones sociales, y que no es, por lo tanto, humano. De esa forma, desde la perspectiva nativa, no se puede decir que ha ocurrido un homicidio, pues eso que permaneció en la tierra no era una vida humana (SEGATO, 2011, p. 365).
}

Para Neves, essa concepção de vida é distinta do conceito de vida cristão e se torna impossível impor concepções externas sobre a vida e a morte. Situação de extrema complexidade "não apenas de um ponto de vista antropológico-cultural ou antropológicojurídico, mas também na perspectiva específica de um direito constitucional sensível ao transconstitucionalismo" (NEVES, 2014, p. 204).

De acordo com Neves, a referida situação produziu 'um caso singular de 'diálogo' e colisão transconstitucional entre ordem jurídica estatal e ordens normativas locais das comunidades indígenas" (2014, p. 203). Assim, Segato contribuiu para o "esclarecimento dessa colisão de ordens jurídicas, enfatizando a necessidade de um diálogo entre ordens normativas, em termos que se enquadram em um modelo construtivo de transconstitucionalismo" (2011, p. $370)$.

\section{TRANSCONSTITUCIONALISMO COMO FORMA DE DIÁLOGO}

Quando se trata de transconstitucionalismo, consiste em "delinear as formas de relação entre ordens jurídicas diversas" (NEVES, 2009, p. 115). Assim, como no caso tratado por este artigo, a ordem jurídica constitucional e a ordem costumeira indígena.

Dessa forma, os conflitos transconstitucionais surgem e são encarados fora das instâncias de natureza judiciária, desenvolvendo-se no âmbito jurídico, executivo e legislativo, 
“assim como no campo dos organismos internacionais e supranacionais não judiciais, dos atores privados transnacionais e, inclusive, especialmente na América Latina, no domínio normativo das comunidades ditas "tribais"” (NEVES, 2014, p. 194).

A "conversação" resultante do transconstitucionalismo, que se define por uma comunicação rigorosa transversal que atravessa fronteiras "não deve levar a uma ideia de cooperação permanente entre ordens jurídicas, pois são frequentes os conflitos entre perspectivas judiciais diversas" (NEVES, 2009, p. 117).

Importante lembrar que nem todo conflito de ordens jurídicas ocorre em tribunais. O conflito fora dos tribunais pode ser considerado "a forma mais relevante de transversalidade entre ordens jurídicas” (NEVES, 2009, p. 118). Nesse sentido Mauricio Salvadori Carvalho de Oliveira aborda a comunicação transversal como uma "dimensão do próprio direito interno do que para o surgimento de um novo direito uno e coerente" (2012, p. 2296). Ou seja, a possibilidade de entendimento de ordens jurídicas dentro do sistema jurídico brasileiro.

No transconstitucionalismo, "as ordens se inter-relacionam no plano reflexivo de suas estruturas normativas que são autovinculantes e dispõem de primazia" (NEVES, 2009, p. 118). Assim, não compete falar de hierarquia entre estruturas e sim, a "incorporação recíproca de conteúdos implica uma releitura de sentido à luz da ordem receptora. Há reconstrução de sentido, que envolve uma certa desconstrução do outro e uma autodesconstrução" (NEVES, 2009, p. 118).

Diante do relatado, resta saber quando questões constitucionais proporcionam o transconstitucionalismo? Neves explica que primeiramente é preciso desvincular a noção de direito constitucional do conceito de Constituição, pois esta apenas surgiu para determinar direitos e garantias fundamentais e para limitar e controlar o poder estatal (2009, p. 120).

Com o surgimento de relações de demasiada complexidade, o constitucionalismo necessitou observar para além do Estado, "os problemas dos direitos fundamentais ou dos direitos humanos ultrapassaram fronteiras, de tal maneira que o direito constitucional passou a ser uma instituição limitada para enfrentar esses problemas (NEVES, 2009, p. 120). O tratamento de conflitos precisou passar a ser problemas de outras normas jurídicas.

O problema não reside no surgimento de conflitos resultantes das ordens jurídicas, mas sim na incompatibilidade das plausíveis soluções oferecidas, "daí por que a busca de 'pontes de transição' é fundamental" (NEVES, 2009, p. 128). Ocorre que as denominadas pontes não são construídas de forma estável no âmbito do transconstitucionalismo, exigindo uma postura 
de construção e de desconstrução de ordens. Dessa forma Neves apresenta o constitucionalismo inicialmente,

\begin{abstract}
como semântica político-jurídica que reflete a pressão estrutural por diferenciação entre política e direito no âmbito da emergente sociedade multicêntrica da modernidade. Mas a semântica constitucionalista reagiu construtivamente no plano das estruturas, servindo como 'ideologia' revolucionária para o surgimento das Constituições como artefatos possibilitadores e asseguradores da diferença entre sistemas político e jurídico (2009, p. 53).
\end{abstract}

Neves apresenta o transconstitucionalismo como um "constitucionalismo relativo a (soluções de) problemas jurídico-constitucionais que se apresentam simultaneamente a diversas ordens" (2009, p. 129).

O lado relevante do transconstitucionalismo para este artigo aponta para relação problemática transconstitucional entre a ordem normativa de comunidades indígenas e a ordem constitucional brasileira, cujo pressuposto nativo cultural entra em conflito com o modelo jurídico do Estado. Evidentemente, o conflito surge porque a ordem normativa dos grupos indígenas não possui princípios ou regras enquadradas no modelo constitucional. Nesse sentido, Neves explica que as ordens normativas indígenas "não admitem problemas jurídicoconstitucionais de Direitos Humanos e de limitação jurídica do poder” (2014, p. 201).

O ponto de vista da coletividade indígena é rígido ao não admitir conflito com a ordem jurídica estatal e, ademais, exigem uma espécie de transconstitucionalismo unilateral de tolerância. Esse transconstitucionalismo mencionado impõe-se porque - embora as ordens jurídicas se distanciam do poder do sistema jurídico da sociedade mundial - a simples anuência "unilateral de direitos humanos aos seus aos seus membros é contrária ao transconstitucionalismo (NEVES, 2014, p. 201). Importante observar o paradoxo resultante desse conflito. O transconstitucionalismo

\footnotetext{
se envolve em "conversações" constitucionais com ordens normativas que estão à margem do próprio constitucionalismo. Mas essa situação é resultante da necessidade intrínseca ao transconstitucionalismo de não excluir o desenvolvimento de institutos alternativos que possibilitem um "diálogo" construtivo com essas ordens dos antropológico-culturalmente "diferentes", baseadas milenarmente no território do respectivo Estado (NEVES, 2014, p. 201).
}

Com relação ao caso já apresentado dos índios Suruahá, é necessário considerar a colisão de ambas as perspectivas dos direitos e buscar não realizar injustiça impondo uma ordem sobre a outra. Explica Neves que o contraponto é que de um lado prevalece o direito à autonomia coletiva e de outro predomina o direito à autonomia individual. Para o autor, "simplesmente submeter aquele, considerado expressão de uma forma ética de vida, a este, 
considerado expressão de uma moral universal que se apresenta como base dos direitos humanos, não parece a solução mais oportuna em um modelo de transconstitucionalismo" (NEVES, 2014, p. 204-205)

No caso da criminalização de homicídio de recém-nascido praticado pelas comunidades indígenas proposta pelo Projeto de Lei pode ser considerado uma espécie de genocídio, pois anula direitos culturais indispensáveis (NEVES, 2014, p. 205).

De tal forma, é necessário buscar outros caminhos. Neves aponta que ao transconstitucionalismo, a proposta mais adequada seria garantir a jurisdição étnica para a comunidade indígena para que elabore um caminho para a sua própria discordância $(2014$, p. 205). Nesse sentido, a exigência de que outra pessoa aceite a condição não é abrir mão de seu discurso. (RAWLS, 1990, p. 217).

Segundo John Rawls, pode ser necessário abrir mão de parte das liberdades quando for preciso para transformar uma sociedade de menos afortunados em uma sociedade em que todas as liberdades fundamentais possam ser apreciadas. Sob essas condições, pode não haver uma forma de organizar a efetividade destas liberdades, mas se plausível constituir as mais essenciais (1990, p. 217-218). Ainda, para o autor, a justiça como equidade parece surgir da exigência de que todas as desigualdades sejam justificadas para os menos favorecidos e da prioridade da liberdade (1990, p. 220).

Nesse aspecto, abordam-se Direitos Humanos com a conceituação de Gunther Teubner (2006, p. 327) que divide os direitos fundamentais em três dimensões: os que protegem a autonomia dos discursos sociais, os direitos pessoais que protegem a autonomia da comunicação e, por fim, a dimensão que é utilizada no transconstitucionalismo "como limites negativos sobre a comunicação social, onde a integridade do corpo e da mente das pessoas está em perigo de extinção".

Nesse sentido, o professor Doglas Cesar Lucas explica que, quanto maior for a disputa entre as culturas, maiores serão os desafios para se promover uma relação de complementaridade e de diálogo entre elas. Assim senso, uma sociedade multicultural - na qual inúmeras culturas postulem reconhecimento e tratamento particular - terá de engendrar encontros e diálogos que obriguem mutualmente os indivíduos a participarem de um projeto comum de responsabilidades (2013, p. 185).

As lutas contemporâneas por reconhecimento identitário desafiam substancialmente o direito porque não se pode atribuir juridicamente identidade a alguém, da mesma forma que não se pode obrigar alguém a ter determinada identidade (LUCAS; SPENGLER, 2012, p. 56). 
As identidades mudaram expressivamente as suas narrativas nas últimas décadas. Todo movimento identitário (nacionais, regionais, culturais, sexuais, étnicas, etc.) esteve vinculado a uma exigência de alteridade (LUCAS; SPENGLER 2012, p. 59-60). Nos litígios que envolvem identidade, abordam-se sobre as diferenças em todos os seus aspectos, "uma fala lotada de historicidade que revela e oculta elemento de sua própria condição de diferença, uma fala que se expõe sem medo, que espera ser acolhida e que se propõe a interagir e compreender" (LUCAS; SPENGLER, 2012, p. 60).

Do ponto de vista da antropóloga Segato, cabe ponderar que na perspectiva do transconstitucionalismo, diante dos conflitos das comunidades indígenas, inclusive a prática do infanticídio, “o papel do Estado, na pessoa dos seus agentes, terá de ser o de estar disponível para supervisionar, mediar ou interceder com o fim único de garantir que o processo interno de deliberação possa ocorrer livremente, sem abuso por parte dos mais poderosos no interior da sociedade" (2011, p. 375).

Portanto, Neves observa que "nenhuma forma de apresentação de autonomia de esferas sociais, inclusive das construídas por comunidades nativas não diferenciadas funcionalmente, tem um caráter absoluto, sendo todas relativas no âmbito da sociedade mundial do presente" (2014, p. 206).

Cabe, ainda, afirmar que o conflito não se reduz ao "dilema entre relativismo ético (das culturas particulares) e universalismo moral (dos direitos dos homens), antes aponta para o convívio de ordens jurídicas que partem de experiências históricas diversas" (SEGATO, 2011, p. 375-377), determinando por parte do Estado Democrático uma postura de "moderação relativamente à sua pretensão de concretizar suas normas específicas, quando essas entrem em colisão com normas de comunidades nativas fundadas em bases culturais essencialmente diferentes" (NEVES, 2014, p. 206).

Assim, "quando questões de direitos fundamentais ou de direitos humanos submetemse ao tratamento jurídico concreto, perpassando ordens jurídicas diversas, a "conversação" constitucional é indispensável”. (NEVES, 2009, p. 129).

Dessa forma, Neves doutrina que na contemporaneidade o transconstitucionalismo "não é capaz de levar a uma unidade constitucional do sistema jurídico mundial. Mas ele parece que tem sido a única forma eficaz de dar e estruturar respostas adequadas aos problemas constitucionais que emergem fragmentariamente no contexto da sociedade mundial hodierna" (2009, p. 122). Portanto, 
o transconstitucionalismo parece ser a alternativa mais promissora para a fortificação de sua dimensão normativa. As ordens estatais, supranacionais, transnacionais e locais, consideradas como tipos específicos, são incapazes de oferecer, isoladamente, respostas complexamente adequadas para os problemas normativos da sociedade mundial (NEVES, 2009, p. 131).

Os mencionados conflitos sugerem a existência de diálogo, que notadamente, não é atingido pelas decisões proferias pelos tribunais. No assunto em questão das culturas indígenas e da ordem constitucional, nota-se que é preciso abandonar a ideia de identidade absoluta e inegociável e respeitar o sentido de ser outro (LUCAS; SPENGLER, 2012, p. 61).

\section{A MEDIAÇÃO E O DIÁLOGO INTERCULTURAL NA RESOLUÇÃO DE CONFLITOS}

Como uma medida de solução dos conflitos, a mediação se torna um método de instaurar o diálogo entre os cidadãos ou grupos com diferentes posições antagônicas provocadas pelo conflito. De tal modo Lucas e Spengler citam que "a mediação facilita a expressão do dissenso definindo um veículo que possa administrar a discordância e chegar a um entendimento comunicativo" $(2012$, p. 63). Se a base do conflito é a ausência do diálogo, é por intermédio desse, a melhor opção de tratamento das resoluções dos conflitos.

A mediação pode se ocupar de qualquer tipo de conflito: comunitário, penal, políticos, de realização dos direitos humanos e da cidadania. Para Warat, "a mediação seria uma proposta transformadora do conflito porque não busca a sua decisão por um terceiro, mas, sim, a sua resolução pelas próprias partes, que recebem auxílio do mediador para administra-lo" (2001, p.80).

Para realidades antagônicas e conflituosas, Lucas e Spengler apostam em um diálogo transformador, "aquele que pode ser traduzido em qualquer forma de intercambio que consiga transformar uma relação" (LUCAS; SPENGLER, 2012, p. 63). Assim, o denominado diálogo pode aplicado a indivíduos que estejam afetados com realidades separadas e que almejam modifica-la em uma relação que realidades sólidas se constroem.

Para que haja um diálogo transformador, estabelecido em casos que a comunicação está ausente, é necessário se despojar de preconceitos e de "postura inflexível e olhar para o outro com um mínimo de sensibilidade e disposição para compreendê-lo, respeitando a sua identidade" (LUCAS; SPENGLER, 2012, p. 64).

É nessa linha que a "mediação reivindica a recuperação do respeito e do reconhecimento da integridade e da totalidade dos espaços de identidade e de privacidade do 
outro, repudiando o mínimo de movimento de movimento invasor e dominar" (LUCAS; SPENGLER, 2012, p. 64).

Para que o procedimento da mediação cumpra a sua finalidade, é necessário falar de alteridade. Para o pensador Luis Alberto Warat no que diz respeito às transformações dos conflitos, se dá "graças à possibilidade assistida de poder nos olhar a partir do olhar do outro, e colocarmo-nos no lugar do outro para entendê-lo a nos mesmos" (2004, p. 62). Ainda para o autor, o entendimento sobre "a outridade afeta os sentimentos, os desejos, o lado inconsciente do conflito, sem que exista a preocupação de fazer justiça ou de ajustar o acordo às disposições do direito positivo" (2004, p. 62).

Além disso, “os conflitantes podem/devem ser encorajados a ouvir e a entender os pensamentos e sentimentos uns dos outros sobre a situação, a gerar opções múltiplas e a trabalharem juntos para chegar a uma resposta que seja adequada para ambos" (LUCAS; SPENGLER, 2012, p.68).

Para Rosângela Angelin e Celso Gabatz, o ordenamento jurídico deve ser multicultural e, ainda "se a dignidade humana não for reconhecida e protegida, não haverá democracia e, ao não existir democracia, a solução dos conflitos sociais não será, de forma alguma, pacifica e equitativa" (2012, p. 84). Assim, é preciso estabelecer o diálogo intercultural e, buscar saídas que sejam debatidas.

Nesse aspecto, "ponderar a dignidade da pessoa humana e da dignidade humana diante do multiculturalismo, visto que cada povo possui uma forma diferente de manifestação cultural e, portanto, de valores diante da vida e da sociedade constituída" (ANGELIN; GABATZ, 2012, p.84).

A questão do multiculturalismo reside no fato de que nos compete tolerar e dialogar entre a igualdade e diferença. Angelin e Gabatz citam que

\footnotetext{
por estarem todas as culturas envolvidas umas com as outras, toda a humanidade é responsável pela evolução cultural de todos e todas. Porém, não nos compete, sob qualquer alegação de ordem econômica, cultural, religiosa, filosófica ou política, acreditar que exista uma cultura melhor, mais completa ou autêntica e, diante disso, querer "ensinar" como cada grupo cultural deva se comportar diante do mundo e os mais variados interesses. Uma postura de alteridade pressupõe o respeito às diferenças, e ao mesmo tempo, a capacidade para vislumbrar o que é contra a dignidade humana, ou o que é produto do próprio preconceito ou interesse pessoal (2012, p. 85)
}

A mediação, neste caso, é mais uma “necessidade do que uma escolha; é condição de possibilidade para a convivência democrática das diferenças. A mediação permite reconhecer a 
historicidade que caracteriza o fenômeno "identidade", o que é fundamental" (LUCAS; SPENGLER, 2012, p.69).

Os conflitos, não se resumem a uma escolha dos membros de uma mesma nação, a uma mesma comunidade, a uma mesma tradição, “em que passe esse tipo de litígio continuar sendo marcante, mas engendra outros tipos de disputas pelo quebramento das noções tradicionais de autoridade, de respeito e de reconhecimento" (LUCAS; SPENGLER, 2012, p.70).

Nessa direção, os conflitos se tornam multifacetados, pois "operam diferentes racionalidades que disputam entre si em ambientes comuns e também distintos" (LUCAS; SPENGLER, 2012, p.70). Os índios, por exemplo, aclamam, também, sua condição de pertença dentro do Estado; reclamam também, melhores condições de trabalho; e poderiam reclamar ainda suas falta de representatividade dentro do Congresso Nacional. Lucas e Spengler aludem que os conflitos identitários "são conflitos que surgiram com o vir à fala das diferenças e dos diferentes e somente um procedimento que estimule a fala e o compromisso com a diferença poderá dar conta da envergadura desse tipo de embate" (2012, p. 70).

A mediação pode ser uma grande estratégia para a ratificação mútua entre as diferenças na luta por reconhecimento. Por isso, Lucas e Spengler, referem a importância, no campo jurídico, "explorar as potencialidades normativas que responsabilizam o humano, que exploram as noções de compromisso e que vinculam o homem com o outro igual em direitos" (2012, p.70).

Mediar divergências com dialogo significa "apelar para o estatuto ético e normativo de responsabilidades recíprocas e escancarar a igualdade ética e jurídica dos diversos tipos de sujeitos e suas diferentes modalidades identitárias" (LUCAS; SPENGLER, 2012, p.70). São necessárias políticas que estimulem as demandas por reconhecimento, ou seja,

\footnotetext{
conhecer o outro é condição de possibilidade para reconhecê-lo. O julgamento jurídico tradicional não se ocupa do outro em sua "outridade", não se importa com as diferenças em conflito e tampouco valoriza a dimensão identitária que veladamente ou escancaradamente constituem os sujeitos do processo. Não que a mediação acabe em uma só ação com essa indiferença mórbida, mas pode por aventura bem sucedida de se encarar institucionalmente os problemas de frente, como eles realmente povoam a realidade substancial dos conflitos que buscam resposta estatal (LUCAS; SPENGLER, 2012, p.70).
}

Entender o conflito como um modo de existência no mundo é condição essencial para poder mediá-lo. Compreender a origem dos conflitos em suas raízes temporais, “é reconhecer a historicidade que está presente no conflito enquanto afirmação de uma posição de mundo que 
se constitui e que se apresenta como resultado de um modo de ser" (LUCAS; SPENGLER, 2012, p.70). Afinal, se torna muito difícil mediar, dialogar, sem a nitidez dos pontos históricos que formam determinados litígios.

Contemplar as diferenças sendo tratadas com equidade ética e normatividade é o que gera força as demandas por reconhecimento. "Inobstante se possa concordar ou não com as práticas identitárias de autoridade, dominação e reprodução sociais, é imperioso compreender seus processos constitutivos e informadores" (LUCAS; SPENGLER, 2012, p.71).

Lucas e Spengler, indagam que a moralidade comporta produzir julgamentos de cunho "ético que geram aceitação ou não do ponto de vista moral; mas a historicidade permite a compreensão das identidades e suas demandas como eventos e como acontecimentos mundanos" (LUCAS; SPENGLER, 2012, p.71).

Validamente, dar oportunidades de fala e conduzir procedimentos de diálogos recíprocos, faz com que esses artifícios sejam indispensáveis dentro dos processos em que a mediação "consiga conjugar todos os esforços no sentido de garantir uma troca dialogal rica e potente entre historicidades e compreensões que divergem entre si e que constituem, via de regra, a matéria prima dos conflitos entre as diferentes identidades" (LUCAS; SPENGLER, 2012, p.71).

\section{CONCLUSÃO}

O artigo tratou sobre os conflitos normativos entre as ordens extraestatais, ou seja, dos povos nativos, e as ordens jurídicas estatais. Nesse sentido, analisou-se o Projeto de Lei n. 1057/2007, que trata de tipificar os casos de infanticídio nas comunidades indígenas. Assim, observou-se que existem posicionamentos distintos abordando o tema.

A partir do estudo baseado no transconstitucionalismo é necessário buscar um ponto de encontro entre a cultura indígena e a normatividade brasileira para que ambos dialoguem, possibilitando uma visão de alteridade. Considerando o conflito que perpetua no Congresso Nacional sobre os casos de infanticídio é necessário que se promova mais espaços de encontros culturais para realçar a conversação entre esses.

Essa situação gerou conflitos de posicionamentos, nesse sentido, uma das correntes de pensamentos é que o maior bem a ser protegido é o direito à vida e à saúde a todas as crianças, defendendo que o ser humano é o centro do discurso, embasando-se na Constituição Federal de 1988, em seu artigo 227 e demais tipificações legais. 
Entretanto, para os contrários ao Projeto de Lei, defendem que a proposta é inconstitucional, pois instiga a destruição de identidade cultural de certos povos indígenas. Afirmam que os índios devem ser protagonistas de sua própria história, valorizando o pluralismo cultural existente na nossa nação, conferindo um tratamento constitucionalmente adequado à questão.

Como resultado alcançado, vislumbra-se que, o Projeto de Lei não tem capacidade de resolver uma questão desta monta. Embora a Constituição Federal de 1988 tenha criado normas específicas para os povos indígenas, buscando, com isso, respeitar a diversidade cultural, na realidade nas relações jurídicas dos espaços ocupados por estes povos é diferente e requer um diálogo mais intercultural para resolver algumas questões como o infanticídio.

Assim, é essencial o fortalecimento da mediação no Estado brasileiro como um dos espaços que favorecem o diálogo entre as ordens conflitantes, para garantir uma troca dialogal coerente entre culturas e compreensões que divergem entre si, contemplando as diferenças tratadas com alteridade gerando força nas demandas por reconhecimento. $\mathrm{O}$ transconstitucionalismo e a mediação implicam um olhar sobre a capacidade de se colocar no lugar do outro.

\section{REFERÊNCIAS}

ANGELIN, Rosângela; GABATZ, Celso. Alteridade Indígena: A Aceitação da Diversidade na Promoção da Dignidade Humana. Revista Direitos Culturais do Programa de Pós-Graduação em Direito - Mestrado URI, Campus Santo Ângelo, v. 7, n.12, p. 73-87, jan/jun. 2012.

BARRETO, Maíra de Paula. Universalidade dos direitos humanos e da personalidade versus relativismo cultural. In: Anais eletrônicos do $15^{\circ}$ Congresso Nacional do CONPEDI. Florianópolis: Fundação José Arthur Boiteux, 2006. Disponível em: <http://www.publicadireito.com.br/conpedi/manaus/arquivos/anais/manaus/estado_dir_povos_ma ira_de_paula_barreto.pdf>. Acesso em: 18 ago. 2016. 
BRASIL. Câmara dos Deputados. Projeto de Lei n. 1.057. Relatora: Deputada Janete Rocha Pietá. Brasília: Comissão de direitos humanos e minorias, 2007. Disponível em: <http://www.camara.gov.br/proposicoesWeb/fichadetramitacao?idProposicao=351362>. Acesso em: 18 mai. 2016.

BRASIL. Câmara dos Deputados. Substitutivo ao Projeto de Lei no 1.057/2007, de 16 de maio de 2011.2 Disponível em: $<$ http://www.camara.org.br/proposicoesWeb/prop_mostrarintegra?codteor=872647\&filename $=\operatorname{Tr}$ amitacao-PL+1057/2007>. Acesso em: 26 ago. 2016.

BRASIL. Constituição da República Federativa do Brasil, de 05 de outubro de 1988. Diário Oficial da União. Brasília, 1988. Disponível em: <http://www.planalto.gov.br/ccivil_03/Constituicao/Constituicao.htm>. Acesso em: 14 jun. 2016.

HOLANDA, Marianna Assunção Figueiredo. Quem são os humanos dos direitos? Sobre a criminalização do infanticídio indígena. Dissertação (Mestrado) - Departamento de Antropologia, Universidade de Brasília, 2008. Disponível em: <http://www.livrosgratis.com.br/lerlivro-online-65235/quem-sao-os-humanos-dos-direitos-sobre-a-criminalizacao-do-infanticidioindigena>. Acesso em: 26 ago. 2016.

LUCAS, Doglas Cesar. Direitos Humanos e Interculturalidade: um diálogo entre a igualdade e a diferença. Ijuí: UNIJUÍ, 2013.

LUCAS, Doglas Cesar; SPENGLER, Fabiana Marion. Identidade, Alteridade e Mediação: por uma comunicação inclusiva das diferenças. Revista Direitos Culturais do Programa de PósGraduação em Direito - Mestrado URI, Campus Santo Ângelo, v. 7, n.12, p. 54-72, jan/jun. 2012.

NEVES, Marcelo. Do Diálogo Entre as Cortes Supremas e a Corte Interamericana de Direitos Humanos ao Transconstitucionalismo na América Latina. Revista de Informação Legislativa. N. 201, ano 51, p. 193-214, jan/mar, 2014. Disponível em: <http://www2.senado.leg.br/bdsf/bitstream/handle/id/502958/001002791.pdf?sequence=1>. Acesso em: 10 abr. 2016.

NEVES, Marcelo. Transconstitucionalismo. São Paulo: Martins Fontes, 2009. 
OLIVEIRA, Mauricio Salvadori Carvalho de. Transconstitucionalismo: racionalidade transversal e law \& economics. Revista Eletrônica Direito e Política, Programa de Pós-Graduação Stricto Sensu em Ciência Jurídica da UNIVALI, v.7, n.3, p. 2277- 2304, Itajaí, 2012. Disponível em: <http://siaiap32.univali.br/seer/index.php/rdp/article/view/5586/2990>. Acesso em: 08 jul. 2016.

RAWLS, John. A theory of Justice. Oxford: Oxford University, 1990.

RODRIGUES, Guilherme Scotti. Direitos Humanos e Multiculturalismo: o debate sobre o infanticídio indígena no Brasil. Revista Jurídica da Presidência, v. 15, n. 106, jun/Set, p. 489 a 515 ,
Brasília,
2013.
Disponível
em:

<https://revistajuridica.presidencia.gov.br/index.php/saj/article/view/138>. Acesso em: 05 ago. 2016.

SEGATO, Rita. Que Cada Pueblo Teja los Hilos de su Historia: el pluralismo jurídico em dialogo didáctico con legisladores. In: CHENAUT, Victoria et al. Justicia y diversidad en América Latina: pueblos indígenas ante la globalización. Quito: FLACSO, 2011. Disponível em: < https://www.flacso.org.ec/biblio/catalog/resGet.php?resId=53356>. Acesso em: 03 mai. 2016.

TEUBNER, Gunther. The Anonymous Matrix: human rights violations by "private" transnational actors. The Modern Law Review, Malden, vol. 69, n. 3, p. 327-346, 2006. Disponível em:

$<\mathrm{http} / / / \mathrm{www} . \mathrm{modernlawreview.co.uk/abstract.asp?ref=0026-}$ 7961\&vid=69\&iid=3\&aid=587\&s=\&d=May\%202006 >. Acesso em: 18 mai. 2016.

WARAT, Luis Alberto. O Ofício do Mediador. Florianópolis: Habitus, 2001.

WARAT, Luis Alberto. Surfando na Pororoca: o ofício do mediador. Florianópolis: fundação boiteux, 2004. 